\title{
Texto e têxtil em O livro de travesseiro
}

Andrei Cunha ${ }^{1}$

RESUMO: Este texto é uma proposta de reflexão em três partes sobre o tema "roupa" em O Livro de Travesseiro, de Sei Shônagon (Japão, séculos X-XI), discutindo a importância dos fazeres relacionados ao têxtil na sociedade aristocrática japonesa da Antiguidade; as suas ressonâncias no contexto da moda no século XX; e a maneira como a metáfora escritura-corpo-vestimenta atualiza-se e amplifica-se na adaptação do livro para o cinema. No livro, texto, têxtil e memória confundem-se, formando uma metáfora complexa que é também um comentário sobre a condição feminina na Corte Imperial de Heian. A adaptação da obra para o cinema (O Livro de Cabeceira, de Peter Greenaway, 1996) conta com a colaboração do designer desconstrutivista Martin Margiela, e acrescenta novas camadas interpretativas a esse aglomerado de imagens relacionadas aos atos de escrever, tecer, ler, traduzir, adaptar e desconstruir. O caráter fragmentário da obra literária pode ainda ser lido como em diálogo com o jornalismo de moda do século XX. O ideal estético do okashi, da literatura clássica japonesa, encontra eco no conceito de pizzazz, de Diana Vreeland, assim como no esteticismo da poética modernista. A roupa como metáfora do texto e a ideia de que roupa é texto estão presentes nesses três momentos interpretativos.

PALAVRAS-CHAVE: quimono, Sei Shônagon, Peter Greenaway, desconstrutivismo, okashi, pizzazz.

\section{Text and textile in The pillow book}

ABSTRACT: This text is a three-part reflection upon the theme of "clothing" as it is found in a literary work of Ancient Japan - on the importance of garment-making skills as a device for the production of difference in the context of the Imperial Court; on how the theme from the book resonates in the context of 20th century fashion; and on how it is brought up to date and amplified, working as a metaphor for writing, in the film adaptation of the ancient text. In The Pillow Book of Sei Shônagon (Japan, 10th-11th centuries), text, textile and memory merge into an extended, web-like metaphor that is also a commentary on the status of women in Imperial Heian. The adaptation of the written work for the cinema (The Pillow Book, by Peter Greenaway, 1996) features clothes by deconstructivist Martin Margiela, adding new interpretative layers to this cluster of images, relating them to the acts of writing, weaving, reading, translating, adapting and deconstructing. The fragmentary character of Sei Shônagon's work also resonates with fashion journalism of the 20th century. The aesthetic ideal of okashi, a concept from classical Japanese literature, resonates with 20th century conceptions of fashion, such as Diana Vreeland's pizzazz, and with the aesthetics of modernist poetry. Clothing as a metaphor for text and the idea of clothing as text are present in those three interpretative moments.

KEYWORDS: kimono, Sei Shônagon, Peter Greenaway, deconstructivism, okashi, pizzazz.

Doutorando em Literatura Comparada pelo PPG/Letras da Universidade Federal do Rio Grande do Sul (UFRGS). Email: <andrei.cunha@ ufrgs.br>. 


\section{Tecido, texto, tela}

No dia 21 do segundo mês ${ }^{2}$ do ano de 994, uma dama de honra da Corte Imperial japonesa, novata no serviço, de nome Sei Shônagon, acompanhou a Imperatriz Teishi e seu séquito à cerimônia de Dedicação de Todos os Sutras no Grande Salão do Templo do Palácio Hoko. Sabemos de detalhes da cerimônia e dos acontecimentos daquele dia porque ela anotou o que viu $^{3}$. De alguma forma - e certamente para a memorialista, a julgar pela intensidade do texto - aquele foi o ápice do esplendor da jovem alteza. O relato em si, escrito cerca de dez anos depois do acontecido, quando a autora era uma escritora experiente e quase todo o elenco do acontecimento já morrera ou se encontrava banido da capital, é hoje conhecido como o Fragmento 260 de $O$ Livro de Travesseiro 4 — uma das mais importantes obras clássicas da "era de ouro dos diários femininos da corte" e o livro mais traduzido de toda a literatura japonesa (HENITIUK, 2012).

O trecho que poderia ser designado como o clímax desse fragmento é uma das muitas descrições que autora nos deixou de como a sua senhora estava vestida. Antes do início da cerimônia, a Imperatriz chega em uma magnífica liteira, decorada com cortinas reluzentes e um estandarte de flor de cebola no remate do pináculo. Depois de instalada em seu palanque, ela manda chamar Sei Shônagon e as outras damas 5 .

A Imperatriz surgiu de trás de uma cortina. Estava com as mesmas roupas que eu já havia visto, mas parecia ainda mais deslumbrante. Em que outro lugar se poderia ver uma túnica chinesa de um vermelho vivo como aquele? Sob esse traje, vestia outros, alternando o branco e o verde, e por cima tinha cinco quimonos simples, de seda roxa, um manto chinês vermelho e uma cauda de festa de seda estampada de azul e branco e debruada em ouro. Eu sentia que nada no mundo podia ser comparado à beleza daquelas cores

- Que tal estou? - perguntou-me minha senhora; mas eu não respondi, porque dizer que ela era magnífica já se tornara algo corriqueiro ${ }^{6}$.

(SGK18:260, p.411)

${ }^{2}$ O segundo mês do calendário lunar tradicional japonês não corresponde a fevereiro. Em geral, é descrito como o mês de transição entre o fim do inverno e o início da primavera.

${ }^{3}$ O acontecimento em si é corroborado por outras fontes historiográficas da época (NAGAl, 2011).

4 O Livro de Travesseiro [枕草子, Makura no Sôshi], de Sei Shônagon [清少納言] (Era Heian, séculos X-XI). A adaptação de Peter Greenaway para o cinema se chama O Livro de Cabeceira [The Pillow Book] (1996).

5

Exceto quando nomeado o tradutor, todas as traduçães propostas aqui são de minha autoria. A referência usada é a edição crítica da obra pela editora Shôgakukan (SEI, 2011), designada aqui pela abreviatura SGK. O número 18 é o volume da coleção de clássicos que corresponde a O Livro de Travesseiro. O número que vem após os dois pontos designa o fragmento (dan em japonês, section em inglês), seguido de "p." e da página em que o trecho se encontra no volume. Nenhuma edição de O Livro de Travesseiro corresponde totalmente a outra na divisão e numeração de fragmentos - é uma das mais famosas dificuldades editorias e tradutórias da obra. $\mathrm{O}$ mesmo Fragmento 260 da edição crítica é referido no filme de Greenaway como Section 150 (vide Figura 1).

6 まだ御裳、唐の御衣奉りながらおはしますぞいみじき。くれなるの御衣どもよろしからむやは。中に唐綾の柳の御衣、葡萄染の五重がさねの織 物に赤色の唐の御衣、地摺の唐の薄物に、象眼重ねたる御裳など奉りて、ものの色などは、さらになべてのに似るべきやうもなし。我をばい かが見る。」と仰せらる。「いみじうなむ候ひつる。」なども、言に出でては世の常にのみこそ。 
Aqui, há três linhas que se entretecem: o fio da palavra (o texto), o fio da seda (o têxtil) e o fio da memória (o travesseiro). A narração se estrutura como uma sucessão de deslumbres - com a beleza da cerimônia, com o nível exaltado da aristocracia ali reunida, com a graça e a inteligência da Imperatriz (assim como o charme masculino de seu pai, o Regente Michitaka), com os penteados, com a maquiagem das presentes, com o refinamento de todos, e com o grande poder daquela família.

Esse fragmento é um importante exemplo das dificuldades que se encontram na tentativa de aproximar um leitor contemporâneo à obra como um todo. A Imperatriz está trajando dez camadas diferentes de roupa. Os trajes de damasco que alternam o branco e o verde são problemáticos - alguns tradutores interpretaram a expressão yanagi ("salgueiro") como fazendo referência a uma cor ${ }^{7}$, quando, na verdade, em japonês antigo, a expressão karaaya no yanagi faz referência a uma técnica de sobreposição de tecidos (kasane) que combina o branco e o verde-claro, imitando as cores do salgueiro e fazendo referência ao prenúncio da primavera. $\bigcirc$ "vermelho vivo" (kurenai) é uma cor tradicional japonesa, e como tal possui ressonâncias importantes, tanto na história artística e literária do país, como nas sensibilidades dos leitores. Era uma cor associada a festividades. Ela é normalmente traduzida em português como "escarlate" ou "carmesim", mas estas palavras têm para mim um repique tão melodramático (associadas que estão ao crime, à prostituição, à sexualidade) que preferi usar algo mais simples.

Os desafios tradutórios desse curto parágrafo não se limitam à questão da sobreposição de camadas. A palavra "quimono" em si já é um problema difícil de ser resolvido: note que ela não aparece no texto de partida, apenas no de chegada. O nosso "quimono", da língua portuguesa, ainda que venha do japonês, é um falso cognato, pois a palavra kimono só se tornou corrente e importante no Japão a partir do século XIX, devido à necessidade de se criar um termo abrangente para as roupas manufaturadas para exportação ao Ocidente ${ }^{8}$. O uso da palavra pela moda ocidental fez que ela adquirisse novos significados e usos como robe de chambre, signo de erotismo, e posteriormente como uma peça bastante diferente das roupas japonesas, a começar pelos manteaux-kimonos de Paul Poiret na década de 1910, passando pelas batas de Balenciaga e pelos casacos de corte reto de Yves Saint-Laurent. $\bigcirc$ atual quimono japonês, aliás, é muito diferente das roupas dos nobres da Era Heian. Jamais ocorreria a Sei Shônagon, nem a um professor do ensino médio no Japão, empregar a palavra kimono no contexto de $O$ Livro de Travesseiro. Por outro lado, o uso brasileiro da palavra brasileira "quimono" é útil, porque o termo pode ser usado com o significado de "roupa japonesa", e talvez atrapalhe menos a leitura do que outras soluções que se apresentam, como "casaco", "manto", "túnica", "traje", "vestido". Nenhuma dessas palavras significa exatamente o que se está querendo traduzir, mas algum tipo de escolha precisa ser feito para que o texto exista.

7 Morris (SEI, 1971, p.231): "a willow-green robe of Chinese damask"; Beaujard (SEI, 2000, p.277): "en damas de Chine, couleur de saule".

8 Kimono [着物]. "O termo 'kimono' [...] (literalmente, "coisa de vestir") deriva sua atual definição [do fim da década de 1860]. Por séculos, a roupa mais comumente usada no Japão foi uma variante do quimono em forma de T, mas essa peça era referida como kosode, ou 'vestimenta com pequenas aberturas nas mangas' [os punhos]. Antes da década de 1850, quando a roupa ocidental ainda não havia entrado para o imaginário nipônico, a maioria dos japoneses se referia a cada peça de roupa pelo seu termo específico" (MILHAUPT, 2014 , p.21). No Brasil, também se utiliza a palavra "quimono" no contexto das artes marciais; no entanto, um judoca japonês preferiria a palavra judôgi [柔道着] para designar seu uniforme. 
Outra questão bastante interessante é o caso da "seda adamascada" ou "damasco". Em princípio, um purista poderia argumentar que não faz muito sentido usar aqui essa expressão, porque a palavra "damasco", significando "tecido de seda com desenhos formados pela alternância de fios foscos e acetinados" entrou para a língua portuguesa por via do árabe, fazendo alusão a um tipo de pano que era originalmente fabricado na cidade persa de Damasco. Ela pertence a um grupo de palavras portuguesas - como "alpendre", "rosário", "sermão", "pão de ló", "xamã" e "romance" — que, mesmo possuindo referentes na cultura japonesa, soam inapropriadas nesse contexto devido ao peso cultural que têm para nós. Estamos a uma distância considerável daquilo que normalmente se considera como a "fidelidade ao original" que o público leigo espera do tradutor.

Assim como o quimono, $O$ Livro de Travesseiro começou a ser conhecido fora do Japão ao final do século XIX, depois da abertura dos portos (a Restauração Meiji é de 1868). 0 primeiro tradutor foi o austríaco August Pfizmaier, que em 1876 publicou um artigo sobre a obra, acompanhado da tradução para o alemão de cerca de vinte páginas escolhidas. A primeira edição (de trechos selecionados) em forma de livro é de 1928, traduzida pelo importante orientalista britânico Arthur Waley. A primeira tradução completa é de André Beaujard para o francês, publicada em 1934 (HENITIUK, 2012). Quando, exatamente mil anos depois dos fatos narrados ${ }^{9}$, o diretor galês Peter Greenaway adaptou a obra de Sei Shônagon para o cinema, ele manteve a ideia de deslumbramento estético associada ao Fragmento 260 e amplificou as ramificações têxteis e anamnésicas do relato, sobrepondo ao tramado do texto e ao tecido da tradução ainda mais uma camada de brocado - a tela, a adaptação para o cinema - , formando o que poderíamos descrever como uma aglomeração complexa de metáforas associadas:

[... A Imperatriz se encontra] rodeada pelo seu séquito em um alpendre de madeira, diante de um jardim de areia. A voz [...] da tia de Nagiko lê um trecho do diário de Sei Shônagon.

SHÔNAGON (A TIA DE NAGIKO) (EM JAPONÊS)

A Imperatriz surgiu de trás de seu cortinado. Ainda estava trajando o mesmo casaco chinês. E em que outro lugar se poderia ver um vestido chinês de um vermelho - vivo como aquele? Sob o casaco, ela estava usando um vestido de brocado verde-salgueiro, cinco camadas de vestidos sem forro cor-de-uva, um vestido de musselina chinesa sobre um forro branco, e uma saia de gala de brocado de seda cinza-azulado. Eu senti que nada no mundo poderia se comparar à sua beleza ${ }^{10}$. (GREENAWAY, 1998, p.32)

O filme começou a ser rodado em 1994, foi finalizado em 1995 e lançado comercialmente em 1996. Parte da ação do filme se passa "no futuro", ou seja, a partir de 1997, quando Hong Kong já não pertencia mais à Grã-Bretanha.

10 The

Empress emerged from her curtain of state. She was still wearing the same Chinese jacket. Where else would one ever see a crimson Chinese robe like this? Beneath it, she wore a willow-green robe of Chinese damask, five layers of unlined robes of grape-colored silk, a robe of Chinese gauze over a plain white background, and a ceremonial skirt of elephant-eye silk. I felt that nothing in the world could compare with her beauty. 
O texto de Greenaway é baseado na tradução para o inglês de Ivan Morris (SEl, 1971, p.231), com algumas simplificações. O texto clássico japonês não foi usado na cena; o texto em inglês do roteiro foi traduzido para o japonês moderno para o filme, criando uma vertiginosa espiral de reescrituras. Ocorre uma interessante cisão entre imagem e palavra, pois se por um lado a personagem mantém o "erro" de dizer "brocado verde-salgueiro", por outro, a designer de figurino do filme, Wada Emi ${ }^{11}$, pôs em cena a sobreposição verde-branco.

O roteiro do filme apresenta esse trecho do livro no contexto de "um desfile de moda extravagante [...] em 1997, [...] em um jardim ornamental, anoitecer, exterior, verão, cor" (GREENAWAY, 1998, p.32). Em um dos muitos deslocamentos por que Greenaway faz o texto passar, a passarela do século XX em Hong Kong serve de moldura para uma cena do século X no Japão, amplificando seus significados e sinalizando os pontos dialogantes entre o sistema da moda da Era Heian e aquele do mundo globalizado do mais recente fin de siècle (vide Figura 1):

Para complementar e contrastar o desfile de moda do século XX com ideias históricas relacionadas à moda das classes privilegiadas, no centro e na parte superior da tela há uma picture in picture que ilustra uma das muitas imagens de O Livro de Travesseiro de Sei Shônagon. Esse livro é o diário íntimo de uma dama de companhia da corte da Imperatriz Sadako [Teishi], na Era Heian, no Japão. O diário e sua autora, Sei Shônagon, assombrarão as atividades do filme, gerando um grande número de alusões e ressonâncias, a ponto de o espectador passar a identificar Nagiko [a protagonista do filme] com a própria Sei Shônagon. (GREENAWAY, 1998, p.32)

1 Wada Emi. Designer de figurinos para o cinema, teatro e ópera, colaboradora de Kurosawa em Ran (1985) — pelo qual ela ganhou um Oscar. Responsável pelo guarda-roupa do filme anterior de Greenaway, A Última Tempestade (1991), e por boa parte do figurino de inspiração tradicional japonesa de O Livro de Cabeceira. 
Figura 1 . O desfile e a Imperatriz.
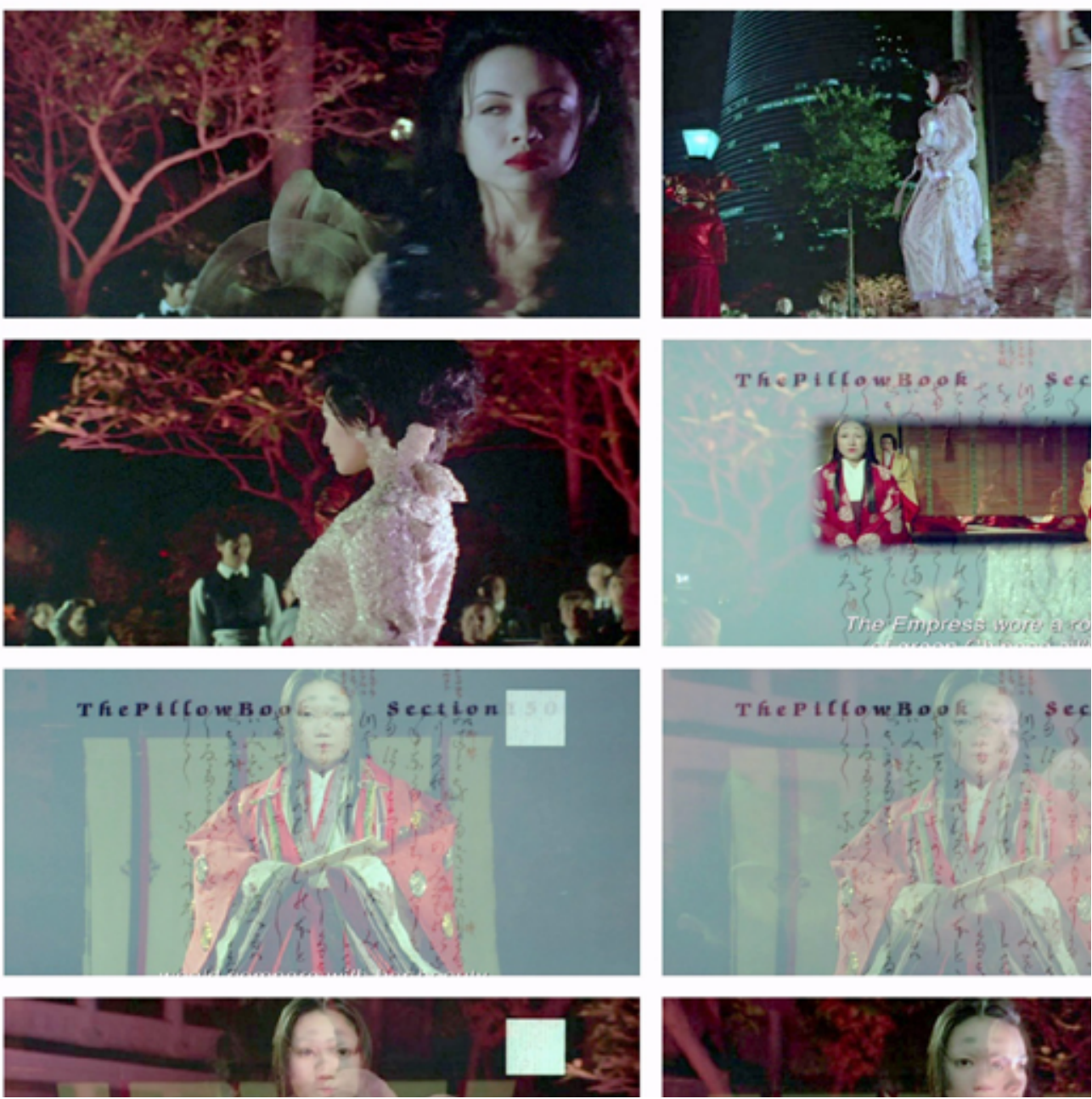

Fonte: O Livro de Cabeceira (DVD, adaptação).

Também no plano da obra cinematográfica, encontramos uma problematização da questão da "fidelidade ao original". Para o diretor, "o cinema não é uma desculpa para ilustrar a literatura" (GREENAWAY, 2004, p.12). A pesquisa mais recente na área de estudos de adaptação rejeita a ideia de que a sua principal tarefa seria a de comparar texto e filme, à procura de "erros" (por exemplo, segundo LEITCH, 2008); no caso de O Livro de Cabeceira, essa noção faz ainda menos sentido, porque Greenaway não busca ilustrar o texto de Sei Shônagon, e sim colocar imagem e palavra em uma espécie de diálogo, jogando justamente com o caráter fragmentário do antigo livro japonês. $\bigcirc$ filme propõe a visualização de conceitos: assim, as imagens de corpos nus revestidos de escrita remetem à materialidade da literatura, à corporalidade do livro, e também à textualidade do corpo.

No livro, a roupa da Imperatriz é muito obviamente um texto: ela se apresenta para nós na forma de palavras; além disso, para as pessoas que a viram naquela tarde de 994, cada camada de seda de suas roupas tinha significados muito precisos, como uma lista de dis-

T tinções e elementos identitários. No filme, na cena em questão, a imagem da Imperatriz 
vem escondida por uma cortina, à qual se sobrepõe uma moldura com o texto em japonês, o título do texto em inglês, imagens do desfile de moda e uma picture in picture de outro texto em japonês. Com esse amálgama de diferentes tipos de imagem, Greenaway propõe uma visualização da atividade do leitor: as palavras do livro antigo não são apenas transformadas em um novo texto, e sim acrescidas de novas camadas de sentido a cada leitura, como uma roupa da Imperatriz. As novas camadas às vezes realçam, às vezes escondem, às vezes emolduram os significados antigos; e o texto japonês, escrito na vertical, apresenta-se ao olho ocidental como um véu - a cortina de trás da qual emerge a soberana. A tarefa do tradutor (que é um tipo especial de leitor) consistiria, para alguns, em descortinar o sentido guardado por trás de todas essas barreiras translúcidas. No entanto, a cada nova interpretação, os leitores, os tradutores e os adaptadores vão criando mais textos e tecidos, que contribuem para a progressiva indefinição dos signos.

No filme de Greenaway, a carreira profissional de Nagiko, a protagonista, inclui um período como contadora de um ateliê de alta costura (uma releitura de uma das funções das damas da corte do século X); posteriormente, ela se torna modelo, trajando, na cena descrita acima, roupas criadas por Martin Margiela. Trata-se talvez de um dos comentários mais "lineares" e, por assim dizer, "fiéis ao original" propostos por Greenaway: a obsessão do século XX com o vestir e o apresentar-se tem pontos em comum com a da Era Heian.

Margiela pode ter sido escolhido para ser o couturier de Nagiko ${ }^{12}$ por se tratar de um representante da moda desconstrutivista ${ }^{13}$. O desconstrutivismo têxtil teria em comum com a desconstrução do texto uma desconfiança com relação ao próprio objeto de sua atividade: a roupa dos desconstrutivistas é constantemente questionada (Isso é um terno? Por quê? Quais os elementos necessários para que algo seja chamado de terno? Quais elementos podem ser omitidos? Quais podem ser substituídos por outros? E quando dizemos ironicamente, "Isso é um terno?", o que quer dizer o terno da nossa ironia?), tratada como um emaranhado de significantes que podem ser descosturados, que podem sofrer deslizamentos de uso ou sentido (LOSCIALPO, 2011).

Para a Sei Shônagon histórica, a roupa é parte de um sistema coerente de significantes que se articulam a partir de noções de classe, gênero e idade - e esse sistema abrange mesmo a natureza e sua interpretação poética. No entanto, em tradução e em adaptação, o seu texto passa por deslizamentos semelhantes aos que Margiela impõe às suas criações. Um leitor mais exigente pode querer saber se os quimonos da tradução eram "mesmo" quimonos no Japão do ano mil, e o que o tradutor quis dizer ao escolher a palavra "quimono" para traduzir a roupa da Imperatriz ("Quais os elementos necessários para que algo seja chamado de quimono?"). No caso da adaptação, Greenaway faz uso deliberado das associações eróticas que o quimono ganhou no Ocidente, pondo em cena as poses lânguidas das pinturas francesas de coquettes da belle époque "vestidas como orientais" — o que, para um japonês que

\footnotetext{
12 Assim como Jean-Paul Gaultier fora o da personagem de Helen Mirren, em O Cozinheiro, o Ladrão, sua Mulher e o Amante (1989).
}

13 Flavia Loscialpo narra o começo do desconstrutivismo da seguinte maneira: "No início dos anos 1980, surgiu um novo grupo de profissionais de pensamento independente, muitos deles japoneses; esses designers transformaram profundamente a cena fashion. Trazendo a influência do minimalismo da cultura e da arte japonesa, os designers Yohji Yamamoto, Rei Kawakubo (Comme des Garçons), Issey Miyake e, ao final da década, os belgas Martin Margiela, Ann Demeulemeester e Dries Van Noten foram pioneiros da revolução na moda" (2011, p.15). 
estudou $O$ Livro de Travesseiro no contexto escolar, pode parecer muito despropositado. Uma das roupas que Margiela propõe para o desfile do filme é uma revisão atual da profusão de camadas de pano e de texto que Sei Shônagon descreve em seu livro: um emaranhado monocromático de tecido translúcido e armação de arame, que envolve totalmente o corpo de Nagiko, lembrando ainda versão sem cores de a Grande Onda de Kanagawa, de Katsushika Hokusai (década de 1830) (Figura 2).

Figura 2 . A "grande onda" de Margiela.

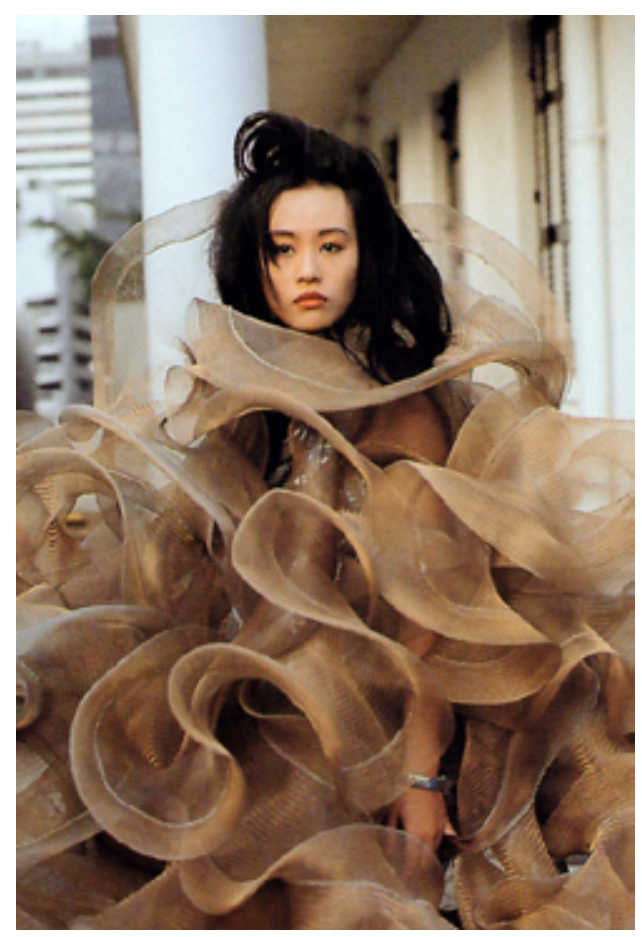

Fonte: Greenaway (1996, p.14).

O "quimono desconstruído" de Margiela/Greenaway chama a nossa atenção para o que tradução e adaptação têm em comum: os dois processos envolvem a criação de um novo texto/objeto que está em diálogo com o texto de partida. Para cada novo texto criado, os textos anteriores ganham novas camadas, refrações e disseminações. Tanto a literatura como o cinema e a moda são pontos de contato entre culturas e textos. Traduzida para o século XX por um diretor britânico, a estética de Sei Shônagon ganha novos significados e põe em diálogo as concepções de roupa e vestimenta da Antiguidade e da pós-modernidade, problematizando a maneira distante como se lê a cultura japonesa tradicional no Ocidente.

\section{Julgando pela aparência}

Diana Vreeland, a influente editora, de 1963 a 1971, da revista Vogue, tinha uma documentada predileção por $O$ Livro de Travesseiro. Talvez essa não seja apenas uma informação trivial. Este é o depoimento de seu bibliotecário: 
exposições dominaram o estilo dos anos 1980 mais do que a influência deste ou daquele estilista. Aqui, nas prateleiras de sua biblioteca, encontramos as histórias da Viena dos Habsburgos, da China Imperial, da Rússia dos tzares, da França na belle époque, da Índia dos marajás, da Inglaterra edwardiana, e dos anos dourados de Hollywood, cada livro representando as investigações de Diana sobre aquelas eras. As Cartas de Madame Sévigné, as Memórias de Saint-Simon, a correspondência de Walpole, os diários dos Goncourt, O Livro de Travesseiro de Sei Shônagon — "Ainda o guardo ao meu lado, junto à cama. Elucubrações da mente, muito encantador. Pequenas vinhetas de sabedoria e beleza". (THOMETZ, s/p)

A enumeração das obras encontradas na biblioteca de Vreeland é interessante como um exercício em Literatura Comparada. Os momentos da história que o bibliotecário menciona - assim como a Nova lorque yuppie dos anos 1980 de onde a memória é extraída - têm em comum a mystique do mais alto esplendor seguido da decadência, momentos da civilização humana sobre os quais se costuma afirmar que alguma espécie de apogeu político, econômico e estético foi atingido, nunca depois igualado, e que serve de referência para o imaginário de outras épocas - menos corruptas ou injustas, talvez, mas desprovidas do glamour desses paraísos artificiais. São sociedades autocráticas, com uma elite sofisticada, privilegiada e ociosa, que podia dedicar muito tempo e reflexão ao trabalho de criar diferenças - estéticas, de classe, de corpo, de cerimonial.

Os livros mencionados, todos igualmente fruto de sociedades elitistas, têm ainda em comum o fato de serem de prosa de não-ficção. Madame de Sévigné e Saint-Simon, contemporâneos e cronistas da corte de Luís XIV, são ambos conhecidos por suas descrições de eventos de gala e de roupas suntuosas e por suas finas observações dos costumes de sua época. Tanto Horace Walpole como os irmãos Goncourt poderiam ter sido lembrados pelas importantes obras de ficção que criaram — o inglês é autor do primeiro romance gótico, e os franceses são nomes centrais do romance naturalista -, mas é o caráter autorreferencial dos títulos escolhidos que parece ter atraído Vreeland.

Em momentos de alto luxo e gala, as sociedades tendem a criar situações de espetáculo em que o público e o privado se entrelaçam, como nas páginas de um diário artístico. $\bigcirc$ Rei-Sol e a Imperatriz do Japão representam, na construção hierática, no modelamento da postura, na pintura do rosto, e na escolha dos símbolos de sua indumentária, aquilo que Susan Gubar (1981) descreve como a utilização do próprio corpo como mídia e objeto de arte (e sujeito de política). Analogamente, para muitos, a não-ficção precisa de justificativas "extraliterárias" 14 para a sua existência — o testemunho de um momento importante da história; a conhecida beleza ou refinamento de seu autor; a sua proximidade de um centro de poder ou de amigos célebres; a descrição de uma condição humana em primeira mão por alguém que "esteve lá"; etc. A ficção, por contraste, é um tipo de texto que pode ser percebido como "mais democrático" (ou melhor adaptado ao modo de produção capitalista)

ponto de vista da teoria da literatura, eu não acredito em distinções binárias do tipo "domínio do literário" versus "trivialidades extraliterárias". Estou aqui me referindo à retórica, talvez exclusivamente regional europeia, da separação do autor de literatura de sua existência em outros âmbitos. Para uma discussão detalhada da atipicidade do conceito europeu de autor frente à literatura do mundo, vide Miner (1990). 
porque, ao tratar a figura do autor como um elemento a mais na criação do artefato livro, se apresenta como homogeneamente disponível a todos os que podem ler e, teoricamente ao menos, como uma empreitada possível mesmo aos autores que por um motivo ou outro não desejam revelar sua identidade. Por exemplo, é muito mais simples ser homem e pretender-se mulher, ou vice-versa, quando se é autor de ficção do que de não-ficção ${ }^{15}$; e o uso de pseudônimos em textos autorreferenciais é uma operação discursiva com consequências muito diferentes das do uso de um "nome artístico" para a escritura de romances.

Uma das criadoras da moderna revista feminina de moda, Vreeland compreendia que o apresentar-se em sociedade era um tipo de performance com raízes históricas nos costumes da nobreza tradicional. Para criar diferenças, as elites autocráticas mobilizam regras estéticas de indumentária, postura, maquiagem, etc., que sejam reconhecíveis e reproduzíveis em diferentes situações. Por outro lado, Vreeland foi uma das primeiras autoras a reescrever esse ideal pré-Primeira Grande Guerra de refinamento e luxo, deslocando-o de um contexto feudal (europeu) para uma sociedade industrial (os Estados Unidos), e substituindo antigas concepções de high society pelo moderno (modernista, pós-romântico) culto da personalidade, tão importante para o desenvolvimento cultural do século XX:

Hoje em dia, a única coisa que importa é a personalidade [...]. Eu não acredito que a revista deva mostrar aquilo que as pessoas chamam de "a sociedade", uma coisa démodée e que praticamente não existe mais [...]. Em vez disso, devemos mostrar personalidades fascinantes, que são a coisa mais interessante que existe no mundo. (VREELAND apud DWIGHT, 2002, s/p)

Vreeland é autora de textos de não-ficção os quais ainda hoje servem de modelo para o genre texto de revista. Seus editorias, assim como seus memorandos internos para o staff, foram reunidos em livros. Antes de se tornar a onipotente editora-chefe de Vogue, no entanto, ela escrevia uma coluna para a Harper's Bazaar, intitulada "Why don't you... ?", com conselhos de estilo para a mulher moderna. Muitos desses conselhos beiravam o nonsense:

Que tal amarrar laços de tule negro em seus pulsos? Que tal mandar fazer sua cama na China - a mais bela cama que se possa imaginar, com a cabeceira e a colcha de cetim amarelo, bordadas de borboletas pousando e alçando voo, de todos os tamanhos e em cores maravilhosas? Que tal enxaguar o cabelo loiro de seus filhos com o champanhe que sobrou da noite anterior, para mantê-lo dourado, como fazem os franceses? Que tal forrar um grande quadro de cortiça, emoldurado em bambu, com feltro cor-de-rosa vivo e ali prender com alfinetes de cabeça colorida todos os seus vários entusiasmos, ao sabor das mudanças semanais em sua vida? ${ }^{16}$ (VREELAND, 2014, s/p)

15 A A Literatura Japonesa tem um exemplo célebre de um poeta homem, Ki no Tsurayuki, que escreveu um diário "como se fosse mulher" - o Tosa Nikki (século X). A problemática em torno dos motivos que o levaram a fazer essa escolha é uma incessável fonte de suposições, mas foge ao escopo deste texto.

16

Why don't you... tie black tulle bows on your wrists? Have your bed made in China - the most beautiful bed imaginable, the head board and spread of yellow satin embroidered in butterflies, alighting and flying, in every size and in exquisite colors? Rinse your blond child's hair in dead champagne to keep it gold, as they do in France? Cover a big cork bulletin board in bright pink felt banded with bamboo, and pin with colored thumb-tacks all your various enthusiasms as your life varies from week to week?

Texto e têxtil em $O$ livro de travesseiro 
Os conselhos podem ser lidos de muitas maneiras diferentes. Para um tipo de leitor, podem parecer, inicialmente, as elucubrações de uma esnobe milionária que tem dinheiro suficiente para gastar em bobagens insignificantes e de alto luxo (mas Vreeland trabalhava, em uma época em que poucas mulheres exerciam cargos de poder, e trabalhava porque precisava do dinheiro). Seguindo essa espécie de raciocínio, esse tipo de vida seria tão vazio e desprovido de significado que suscitaria a necessidade de desejos inúteis, por bagatelas de uma não-funcionalidade imoral e niilista. (Mas existe desejo útil?) Por outro lado, o texto pode ser lido de outras formas. $O$ desejo expresso nessas coisas sem sentido é de um inusitado que lembra as imagens dos surrealistas, ou o alto esteticismo de alguns modernistas. A imaginação nervosa e fantástica por trás desse texto — que se apresenta como jornalístico - é da mesma estirpe das combinações imaginadas de "Desilusão das Dez Horas", de Wallace Stevens - um poema que justamente condena a conformidade sufocante da vida burguesa e regrada (as "camisolas brancas"), e sonha com possibilidades absurdas e cheias de cores, que nunca se realizarão:

\section{[...] As casas são assombradas \\ Por camisolas brancas. \\ Nenhuma é verde, \\ Nem roxa com bainha verde, \\ Nem verde com bainha amarela, \\ Nem amarela com bainha azul. \\ Nenhuma delas é estranha, \\ Com meias de renda \\ E faixas de contas. [...] \\ (STEVENS, 1987, p. $25^{17}$ )}

Esses textos e seus sonhos de cores podem ser lidos também como em diálogo com Sei Shônagon:

COISAS QUE FAZEM O CORAÇÃO BATER MAIS FORTE

Coisas que fazem o coração bater mais forte. A mamãe pardal e seus filhotes. Passar por um lugar onde brinca um bebê. Acender um bom incenso e ir me deitar sozinha. Descobrir que o espelho chinês está arranhado. Quando vejo estacionando na frente da minha casa a carruagem de um homem nobre, que manda um empregado perguntar alguma coisa.

Lavar os cabelos, maquiar-me e vestir um quimono cheiroso. Mesmo que não tenha ninguém para me ver arrumada, eu me sinto ótima. Quando estou esperando uma visita noturna, seguido me assusto com o som da chuva e das portas que o vento chacoalha ${ }^{18}$.

(SGK18:27, p.69-70)

17 Tradução de Paulo Henriques Brito. The houses are haunted / By white night-gowns. / None are green, / Or purple with green rings, / Or green with yellow rings, / Or yellow with blue rings. / None of them are strange, / With socks of lace / And beaded ceintures.

18 心ときめするもの 雀の子飼ひ。ちご遊ばする所の前わたる。よき薰き物たきてひとり臥したる。唐鏡の少しくらき見たる。よき男の車とどめ て案内し、問はせたる。頭洗ひ、化粧じて、かうばしうしみたる衣など着たる。ことに見る人なき所にても、心のうちは、なほいとをかし。待つ人な どのある夜、雨の音、風の吹きゆるがすも、ふとおどろかる。 
A obra de Sei Shônagon é associada, no contexto da História da Literatura japonesa, a um princípio estético da era clássica denominado (w)okashi [をかし]. É comum, no meio acadêmico japonês, estabelecer correlações entre uma dada época ou movimento artístico e um determinado vocabulário estético. Assim, por exemplo, a obra de Bashô pode ser associada ao conceito de wabi-sabi, uma espécie de "beleza da frugalidade" ou "sublime simplicidade". É bastante conhecida a proposta de Haroldo de Campos (2005) de traduzir o yûgen de Zeami por "charme sutil" — o "belo e misterioso" ideal artístico do teatro nô. Essas palavras, no entanto, não se aplicam apenas à literatura, pois as artes no Japão não conhecem uma subdivisão positivista como a cultura europeia das "musas"; e a divisão entre "artes propriamente ditas" e "artes aplicadas" não faz sentido no contexto dos ofícios tradicionais japoneses.

O okashi (wokashi em japonês clássico) de Sei Shônagon era um ideal de beleza, vivacidade e esplendor. A palavra, repetida nada menos que 466 vezes em $O$ Livro de Travesseiro (WAKISAKA; CORDARO, 2013, p.16), refere-se à sensação ou emoção de alegria e de leveza, à surpresa de descobrir a beleza captada num momento apropriado. A partir da Idade Média, a ideia de wokashi passou a significar o engraçado ou cômico, e se tornou o motivo principal do teatro kyôgen. Mais tarde, o conceito foi reivindicado pela poesia renga e haikai19. O okashi tem elementos em comum com o wit ou o esprit europeus, com o dandismo e a sprezzatura, e pode se referir tanto a um humor leve, como a uma sobreposição artística e estimulante de sensações ou imagens, ou ainda a um ideal de performance do corpo:

MONGE TEM QUE SER BONITO

monge que dá o sermão tem que ser bonito. Afinal, os ensinamentos parecem mais profundos quando se olha na cara de quem os diz. Se a gente começa a se distrair e olhar para os lados durante um sermão, esquece logo do que foi dito. Eu me sinto um pouco imoral se o monge é feio $[\ldots]^{20}$.

(SGK18:31, p.72)

COISAS ELEGANTES

Coisas elegantes. Uma menina trajando uma túnica branca sobre outra lilás. Ovos de pata. Gelo raspado com calda de liana, servido em uma taça nova de metal. Um rosário de cristal. Flores de glicínia. Neve sobre a ameixeira florida. Uma criança bonita comendo morangos ${ }^{21}$.

(SGK18:40, p.98)

19 De uma forma ou outra, okashi ainda é uma ideia importante no Japão contemporâneo, que oscila entre uma predileção pelo sublime melancólico (aware) e o prazer do belo (ou o belo do prazer) — hoje, no entanto, esse ideal de leveza é mais associado à cultura do kawaii (bonitinho, meigo).

20 説経の講師は顔よき。講師の顔をつとまもらへたるこそ、その説くことのたらとさもおぼゆれ。ひが目しつればふとわするるに、にくげなるは 罪や得たらむとおぼゆ。

あてなるもの 薄色に白襲の汗衫。かりのこ。削り水にあまづら入れて、新しき金鋺に入れたる。水晶の数珠。藤の花。梅の花に雪の降りかか りたる。いみじううつくしきちごの、いちごなど食ひたる。

Texto e têxtil em 0 livro de travesseiro 
Madalena Cordaro afirma que O Livro de Travesseiro é uma "reflexão profunda entre as metonímias da natureza e da cultura". É como se a arte tivesse por missão organizar os elementos da natureza, prescrevendo, para cada estação do ano, "determinado pássaro, planta, flor, local, hora, vestuário, incenso, poema, papel, cor, música, atitude, como que numa colagem de elementos de diferentes categorias, numa elaboração de um conjunto de justaposições" (CORDARO, 2002, p.48). Nessa estilização, há cortes importantes e escolhas estratégicas: resta da natureza uma versão sem extremos, focando apenas nos aspectos mais suaves, harmônicos e elegantes ("poéticos") da fruição das mudanças do meio ambiente. Da mesma forma, as manifestações culturais - têxteis, desenho, poesia, arquitetura, etc. — refletem essa natureza idealizada e como que fazem parte dela, em um espectro contínuo bastante distinto da maneira antagônica como a cultura regional da Europa construiu essas categorias.

Em sua defesa da vivacidade, leveza e elegância, o wokashi de Sei Shônagon está muito próximo do conceito de pizzazz, uma palavra cuja invenção é atribuída a Diana Vreeland: "uma atraente combinação de vitalidade e glamour" (OXFORD, s/d, s/p) 22. A aproximação de um conceito da história da literatura a outro da moda pode parecer extravagante e incongruente. Por outro lado, algo que os textos aqui propostos têm em comum é uma aparente frivolidade, insulto frequente reservado aos textos de autoria feminina. Mesmo no Japão, onde a poética do diminuto, do doméstico e do cotidiano é aceita como mainstream, Sei Shônagon foi historicamente acusada de superficialidade. Muitos comentaristas da Idade Média, da Era Edo, e mesmo dos séculos XIX e XX, parecem extremamente desconfortáveis diante da "obsessão" da autora pelos fazeres e prazeres femininos. As traduções para línguas ocidentais reproduzem essa visão condescendente. Além de preocupada com coisas consideradas como inúteis, fica claro em $O$ Livro de Travesseiro que a autora se via à altura, ao menos no plano intelectual e sexual, de seus contemporâneos homens, o que levou seus comentaristas muitas vezes a dizerem (refúgio corriqueiro do machismo opressor) que ela era promíscua e insolente - quando, na verdade, o comportamento de Sei Shônagon não tinha nada de extraordinário no contexto social em que ela viveu (HENITIUK, 2011). Abaixo, temos a apresentação que fez Donald Keene (professor da Universidade de Columbia e autor da mais importante História da Literatura Japonesa escrita por um estrangeiro) para um trecho da tradução de Waley que foi incluído em uma antologia pertencente à série de textos clássicos da UNESCO (a primeira edição é de 1955):

O Livro de Travesseiro de Sei Shônagon [...] é uma das mais encantadoras [delightful] obras da literatura japonesa. A autora, contemporânea de Murasaki Shikibu, era uma mulher de notável talento e fino senso de humor [a woman of remarkable talent and wit], e seu livro é, talvez, a abordagem mais próxima da nossa comédia sofisticada [high comedy] no contexto da literatura japonesa. É uma obra sem precedentes, cheia de impressões momentâneas e toques delicados, ainda que lhe falte grande profundidade [if lacking in great depth]. (KEENE, 1996, p.137)

2 Pizzazz (informal). An attractive combination of vitality and glamour. [...] Origin: Said to have been invented by Diana Vreeland, fashion editor of Harper's Bazaar in the 1930s (OXFORD, s/d, s/p). 
texto de Keene (que, eu acredito, seria completamente diferente se escrito em um momento posterior de sua carreira) hoje soa muito condescendente, como se ele achasse necessário pedir desculpas pelo humor de Sei Shônagon - e como se o humor fosse um modo menor, mas nisso ele não está sozinho. Os leitores de Oscar Wilde reconhecerão o mecanismo de diminuição intelectual daquilo que faz rir, usado também contra a obra dele. A descrição parece, a um tempo, tornar Sei Shônagon mais divertida e de menor valor. É como se, com seu estilo bastante jovial, próximo do coloquial, ela estivesse longe do elevado e do sublime.

\section{Roupa e memória}

Diversas passagens de textos da Era Heian descrevem uma troca, ou pagamento de um serviço, tendo por moeda o quimono - preferencialmente, o feminino, pois exigia mais horas de trabalho e expertise em sua confecção (vide Figura 3). $\bigcirc$ artefato concedido a mensageiros ou subalternos em pagamento por serviços ou lealdade não se destinava necessariamente ao uso do recipiente, nem de sua família. A produção de diferença por meio da roupa era uma empreitada coletiva. Ao contrário de outras atividades manuais, essa não era considerada como indigna de uma aristocrata. No Fragmento 260, Sei Shônagon narra como a Imperatriz e seu séquito prepararam-se para a cerimônia da Dedicação de Todos os Sutras.

Dei uma espiada no lado norte do Pavilhão Sul e vi luminárias altas acesas; em torno delas, separados por biombos ou cortinas, havia pequenos grupos de duas - ou três — ou três ou quatro - damas. Outras ainda estavam sentadas em grupos maiores, alinhavando seus quimonos simples em combinações precisas de cores, decorando suas caudas de gala com cordões trançados, ou ainda se pintando com grande cuidado. A maquiagem e os penteados que ali se preparavam eram tão impressionantes que difícil me era imaginar tal beleza um dia repetida ${ }^{23}$. (SGK18:260, p.406)

Ainda nesse fragmento, a autora descreve o momento em que chega uma carta do Imperador. $\bigcirc$ Regente retira-se para providenciar o pagamento do mensageiro (um conjunto completo de trajes femininos de gala). A Imperatriz escreve a resposta: "Sua Alteza escreveu a resposta em um papel muito delicado, lilás e rosa, que ecoava a cor de seus trajes. É uma pena que não existam mais pessoas capazes de apreciar um detalhe como esse" 24 (SGK18:260, p.395).

23 南の院の北面にさしのぞきたれば、高杯どもに火をともして、二人、三人、三四人、さべきどち屏風ひき隔てたるもあり。几帳など隔てなどもし たり。また、さもあらで、集まりみて衣どもとお゙かさね、裳の腰さし、化粧ずるさまはさらにもいはず、髪などいふいもの、明日よりのちはありがたげ に見ゆ。

24 御返し、紅梅の薄様に書かせ給ふが、御衣のおなじ色ににほひ通ひたる、なほ、かくしもおしはかり参らする人はなくやあらむとぞくちをしき。

Texto e têxtil em O livro de travesseiro 
A mulher da aristocracia na Era Heian gerenciava uma série de instrumentos de circulação de poder: a criação de moda e design de vestuário; a aquisição, o armazenamento, o corte e o tingimento de papéis e tecidos; e a acumulação e a mediação de conhecimentos de etiqueta, estilo, genealogia e cerimonial. De uma maneira muito concreta, a mulher nobre tinha carreira e instrumentos de ascensão social, associados a esses saberes e fazeres (CAVANAUGH, 1996; WALLACE, 2005). O Fragmento 260 começa narrando como, instalada no Palácio da Segunda Avenida, a Imperatriz recebe uma visita de seu pai, o Regente Michitaka.

O Regente Michitaka veio visitar minha senhora. Estava vestindo uma calça bufante, de brocado cinza-azulado, com cadarços nos tornozelos. A túnica de cima era branca, com um forro vermelho-escuro, e por baixo havia três quimonos simples, escarlates. A começar pela Imperatriz, todos de nossa casa estávamos vestindo trajes de brocado, seda estampada ou lisa, em tons mais claros ou escuros de roxo ou vermelho-vivo, e o conjunto todo cintilava sob a luz. Os casacos das damas eram verde-claros, brancos com verde, ou roxos com vermelho-vivo ${ }^{25}$. (SGK18:260, p.395)

A leitura mais superficial que se pode fazer do texto é de que ele é superficial - uma descrição fastidiosa e desnecessária das roupas do regente e das damas, que poderia talvez ser omitida de uma tradução condensada. No entanto, essa profusão de vocabulário relacionado ao vestir tem os seus motivos. Trata-se de um dos fragmentos que Sei Shônagon escreveu quando já estava afastada dos centros de poder. O partido de Michitaka e Teishi, a quem ela servia, perdeu a disputa pelas graças do Imperador Ichijô, que se casou com uma filha do adversário do regente. Michitaka morreu muito jovem e não pôde proteger sua família. Seu filho mais velho foi exilado, e Teishi foi enviada para fora do palácio, sendo obrigada a viver de favor na casa de um nobre. Quando finalmente conseguiu dar à luz um herdeiro, sua saúde estava afetada, e ela morreu em seguida. Seu filho foi criado pela Imperatriz do partido inimigo.

O Livro de Travesseiro tem muitos trechos com formato e temática normalmente associados à literatura de testemunho. Alguns autores chegam ao extremo de afirmar que "se trata de um livro no qual Sei Shônagon abandona por completo sua posição e individualidade frente à obra e escreve-a baseada na determinação e na elevada consciência profissional de uma dama de honra" (SHIMONO, 2002, p.15). Esse caráter de documento público e de obra encomiástica dever-se-ia às circunstâncias em que o texto foi escrito:

Enquanto escrevia sua obra, dia a dia seu mundo ia se desmoronando, entre ardis e estratagemas, e, ao terminar de escrevê-la, a realidade que seus olhos encontraram foi a morte da Imperatriz Teishi [...], um clã destruído, a ascensão da [rival e] prima Shôshi à dignidade de Imperatriz, e o triste e patético destino de todo aquele que é vencido no mundo da política e desaparece. (SHIMONO, 2002, p.15)

5 殿わたらせ給へり。青鈍の固紋の御指貫、桜の御直衣にくれなるの御衣三つばかりを、ただ御直衣にひき重ねてぞたてまつりたる。御前より はじめて、紅梅の濃き薄き織物、固紋、無紋などを、あるかぎり着たれば、ただ光り満ちて見ゆ。唐衣は、萌黄、柳、紅梅などもあり。

Texto e têxtil em O livro de travesseir 
Sei Shônagon seria a testemunha do outro lado da história oficial (ou da história dos perdedores), deixando ao mundo o legado de esplendor que era o ideal de seu salon. A catástrofe em si nunca é descrita, e um leitor mais desavisado pode não se dar conta de que toda a suntuosidade da vida da Imperatriz era, para usar uma expressão proustiana, um paraíso que já fora perdido no momento da escritura. É nesse sentido que se devem ler os (raros) trechos do texto em que a autora lamenta o que já passou:

Mas esses eventos, que nos pareciam tão auspiciosos naquele tempo, ganham novo significado se eu penso neles no presente. E é por isso que hoje eu escrevo este relato, tomada de tristeza; ainda que seja impossível descrever tudo o que vivi naqueles dias, procurei deixar aqui o maior número possível de lembranças ${ }^{26}$. (SGK18:260, p.417)

Em campos acadêmicos estabelecidos há mais tempo, como as literaturas nacionais, é frequente a presença de sistemas conservadores de valoração. Assim, critérios como a linguagem "pura" ou "elegante"; os autores tidos como "fortes" ou "influentes"; os gêneros textuais definidos como "autônomos" (e a "hierarquia" que considera como "o mais importante" deles o "romance"); a estrutura com "unidade" e "coesão"; a escolha de temas considerados pela convenção como "sublimes" e a discussão filosófica de assuntos tidos como "sérios" são muitas vezes apresentados como decisivos para a sobrevida de um texto. À exceção da questão da linguagem, todos os outros critérios são problemáticos para a compreensão desse livro: a obra é híbrida quanto ao gênero; a autora é mulher - e esse fato foi objetivamente atacado por séculos de comentaristas e tradutores, japoneses e estrangeiros (HENITIUK, 2011); os fragmentos reunidos não têm ordem, unidade ou coerência; os temas foram repetidamente denunciados como "frívolos" e fruto de "esnobismo"; e não há discussão racional de assuntos "sublimes" ou "filosóficos".

Nesse sentido, a metáfora do têxtil para esse texto tem implicações que vão além do memorial, do documento histórico ou da pintura de costumes. Uma interpretação a partir do moderno e do masculino - como faz, por exemplo, Ivan Morris em sua tradução e introdução - pode enxergar nos temas e nas atitudes de $O$ Livro de Travesseiro uma tendência para a insignificância: "em muitos aspectos, tais como seu amor pelo luxo e pelas cores, o deleite que encontra na poesia, e a mescla de inocência e sofisticação que a caracterizam, ela era muito parecida com as outras mulheres escritoras que conhecemos" (MORRIS, 1971, p.10) $)^{27}$. Os temas não são aqueles esperados de uma obra de literatura "central". Por outro lado, os temas escolhidos só não são "sérios" no sentido ocidental e a partir da perspectiva (de uma perspectiva) do século XX. No meio em que Sei Shônagon vivia, a poesia e a estilização da natureza eram de extrema importância não apenas no campo do literário, mas como uma ferramenta de comunicação e interação social (RAUD, 2003).

26 またの日、雨の降りたるを、殿は、「これになむ、おのが宿世は見え侍りぬる。いかが御覽ずる。と聞こえさせ給へる、御心おごりもことわりな り。されど、その折、めでたしと見たてまつりし御ことどもも、今の世の御ことどもに見奉りくらっぶるに、すべてひとつに申すべきのもあらねば、 もの憂くて、多かりしことどもも、みなとどめつ。

27

Além de condescendente, essa afirmativa pode levar-nos a conjeturar se Ivan Morris conhecia, por exemplo, a obra de Balzac, um homem que amava o luxo e as cores, ou a de George Eliot, uma mulher que repudiava tanto a inocência como o tipo de sofisticação a que ele se refere aqui. 
A mulher erudita e com conhecimentos literários tinha valor "agregado" como "moeda de troca" na "circulação do poder". A literatura e os fazeres associados — a seleção e aquisição de papel, a caligrafia, a correspondência — eram parte da cadeia produtiva (CAVANAUGH, 1996) e criavam diferença e status para quem os detinha. Um homem nobre não tinha como avançar na carreira burocrática sem dominar as artes da escrita, que eram socializadas entre homens e mulheres. Mais importante ainda, um aristocrata não podia atuar na Corte sem se vestir corretamente, de acordo com um código bastante rígido que envolvia considerações de hierarquia, e que mudava segundo a época do ano e a ocasião. Essa codificação do vestir incluía outras exigências que poderiam ser descritas como "sofisticação", "bom gosto" ou "distinção" (no sentido que Bourdieu dá a essa palavra). A roupa e o texto pertenciam a um espectro contínuo de capitais culturais aos quais a mulher nobre tinha acesso - e, no caso da roupa, monopólio. Ainda que o homem pudesse adquirir tecidos, era a mulher que dava a eles significado. É em virtude dessas prerrogativas que não se pode dizer que a mulher da Era Heian era meramente um objeto passivo de circulação de valor, pois ela produzia e era sujeito dessa cultura, em grande medida.

O "deleite da poesia" e "sofisticação" que caracterizam o texto não têm nada de "inocente". Além de ser um testemunho político de uma época, a obra tinha a aspiração de ser um compêndio de ideias estéticas. A posteridade, muitas vezes sob protesto, tratou-o de acordo com essas ambições. É muito difícil escrever uma análise da política palaciana da Era Heian sem citar a obra de Sei Shônagon; mais importante ainda, não é possível falar em estética tradicional (e mesmo contemporânea) do Japão sem passar pelo conceito de wokashi, que tem sua definição mais conhecida nas escolhas artísticas de $O$ Livro de Travesseiro.

\section{Para arrematar}

A roupa como metáfora do texto e a ideia de que roupa é texto estão presentes nos três momentos interpretativos propostos aqui. No Japão antigo, o apresentar-se era parte essencial da vida aristocrática, instrumento da manutenção e obtenção do poder. Os saberes acessíveis à mulher nobre incluíam a produção de quimonos e de literatura. A roupa e o texto eram elementos constitutivos do corpo e da sexualidade feminina, e aqueles desempenhavam papel central nos jogos políticos do palácio. À distância de dez séculos, o texto de Sei Shônagon se apresenta como uma sobreposição de camadas de sentido e de corporalidade, em ressonância com o título da célebre coleção primavera-verão de 1997 da Comme des Garçons ${ }^{28}$ : "Dress becomes Body becomes Dress".

O ideal de beleza e sofisticação - característica das épocas que posteriormente receberam o nome de "clássicas" — tem diferentes manifestações em diferentes épocas; por outro lado, muitas sociedades aristocráticas parecem dar centralidade ao uso do tecido e do texto autobiográfico na construção da subjetividade. Diana Vreeland, que teve importante papel na criação do sujeito contemporâneo de moda, foi capaz de compreender como essas culturas autocráticas e sua obsessão com o espetáculo — seja na forma de roupas, seja na forma de textos autorreferentes - podiam ser ressignificadas pela via do purismo de formas e pela experimentação poética do modernismo, que ela instrumentalizou no texto

28 Da também japonesa Rei Kawakubo, importante nome do desconstrutivismo.

Texto e têxtil em $O$ livro de travesseiro

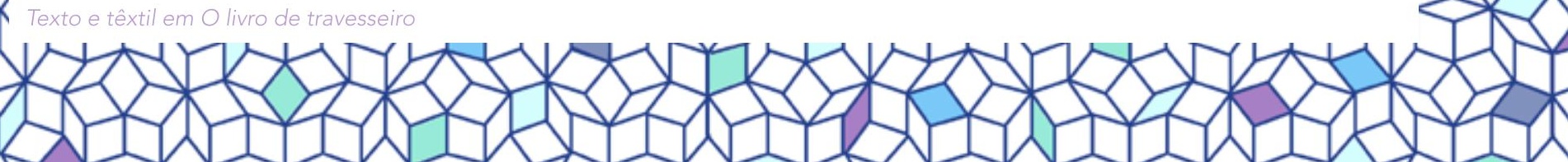


jornalístico e no editorial de moda de revista. A visão de Vreeland, a um tempo elitista e populista, atualiza o ideal de nobreza e de esteticismo de autoras como Sei Shônagon para o capitalismo e o culto da personalidade do século XX.

A crítica proposta pelo desconstrucionismo e pelos artistas da pós-modernidade, como Peter Greenaway, problematiza as questões do ideal de beleza e da estrutura autocrática de produção de subjetividade, associadas aos mais diferentes classicismos e modernismos. Na maneira como Greenaway encena, em O Livro de Cabeceira, a roupa, o corpo e o livro, encontramos uma importante discussão sobre a instabilidade dos conceitos e sobre a maneira como, a cada nova leitura, são acrescentadas novas camadas textuais a palavras como "quimono", de um significado (aparentemente) tão simples, e que revelam, no momento em que são descosturadas, um mar de signos e grandes ondas de significados.

\section{Referências}

CAVANAUGH, C. Text and Textile: Unweaving the Female Subject in Heian Writing. Positions: East Asia Cultures Critique, Durham, v.4, n.3, 1996. p.595-636. Disponível em: <http:// positions. dukejournals.org/content/4/3/595. citation>. Acesso em: 15 jun. 2011.

CORDARO, M. Cronologia de eventos históricos e literários. In: SEI, S. O Livro do Travesseiro. Tradução de G. Wakisaka, J. Ota, L. Hashimoto, L. Yoshida e M. Cordaro. São Paulo: Editora 34, 2013. p.595-607.

Pintura e Escritura do Mundo Flutuante: Hishikawa Moronobu e ukiyoe e Ihara Saikaku e ukiyozôshi. São Paulo: Hedra, 2002.

Sobre a Estética de Okashi na Tradução de O Livro-Travesseiro de Sei Shônagon. Revista de Estudos Orientais, v.5. São Paulo: USP, 2006. p.127-137.

DWIGHT, E. The divine Mrs. V. New York Magazine. Nova lorque, nov. 2002. Disponível em: <http://nymag.com/nymetro/shopping/fashion/features/n_7930/>. Acesso em: 13 ago. 2015. GREENAWAY, P. 105 anos de texto ilustrado. Tradução de Myriam ÁVILA. In: MACIEL, M. (Org.). O cinema enciclopédico de Peter Greenaway. São Paulo: Unimarco, 2004, p. 11-16.

The Pillow Book. Roteiro do filme. Paris: Dis Voir, 1996.

GUBAR, S. "The Blank Page" and the Issues of Female Creativity. Critical Inquiry, v.8, n.2, Writing and Sexual Difference (Winter, 1981). p.243-263.

HENITIUK, V. Prefacing Gender: Framing Sei Shônagon for a Western Audience, 1875-2006. In: FLOTOW, L. (Org.). Translating Women. Ottawa: The University of Ottawa Press, 2011. p.239-262.

Worlding Sei Shônagon: The Pillow Book in Translation. Ottawa: University of Ottawa Press, 2012.

IVANOVA, G. Knowing Women: Sei Shônagon's Makura no Sôshi in Early-Modern Japan, 2012. Faculty of Graduate Studies, Asian Studies, University of British Columbia, Vancouver. Tese de Doutorado. Disponível em: <hdl.handle.net/2429/42801>. 238 fl. Acesso em: 22 ago. 2014.

KEENE, D. Anthology of Japanese Literature. Tóquio: Tuttle, 1996. 
KITAMURA, K.; SUZUKI, H. Makura no Sôshi Shunshoshô. Tóquio: Seisandô, 1925. Disponível em: Biblioteca Nacional do Parlamento Japonês, <http://dl.ndl.go.jp/info:ndljp/ pid/945600>. Acesso em: 6 ago. 2015.

LEITCH, T. Adaptation Studies at a Crossroads. Adaptation, v.1 , n.1, 2008. p.63-77.

LOSCIALPO, F. Fashion and Philosophical Deconstruction: a fashion in-deconstruction. In: WITT-PAUL, A.; CROUCH, M. (Ed.). Fashion Forward. Oxford: Interdisciplinary Press, 2011. p.13-27.

Milhaupt, T. Kimono: a modern history. Londres: Reaktion, 2014.

MINER, E. Comparative Poetics: an intercultural essay on theories of literature. Nova Jérsei: Princeton University, 1990.

MORRIS, I. Introduction. In: SEI, S. The Pillow Book of Sei Shônagon. Tradução de Ivan Morris. Londres: Penguin, 1971. p.9-19.

NAGAI, K. Kaisetsu [解説]. In: SEl, S. Makura no Sôshi. Shinpen Nihon Koten Bungaku Zenshû, v.18. Edição de Kura Toshinori. Tradução e notas de Matsuo Satoshi. Introdução e apêndices de Nagai Kazuko. 7.ed. Tóquio: Shôgakukan, 2011 [primeira edição de 1997]. p.475-509. [新編 日本古典文学全集 18 『枕草子』/校注·訳者—松尾聡, 永井和子 / 発行者 一 蔵敏則 / 発行所 — 小学館]

O Livro de Cabeceira (Título original: The Pillow Book). Direção de Peter Greenaway. Produção de Kees Kasander. Roteiro de Peter Greenaway, adaptado da obra Makura no Sôshi, de Sei Shônagon. 1996 (produção); s/d (DVD). 1 filme (120min), DVD, son., color.

OXFORD Dictionaries. Pizzazz. Oxford: Oxford, s/d. Disponível em: <http://www.oxforddictionaries.com/us/definition/american_english/pizzazz>. Acesso em: 15 ago. 2015.

RAUD, R. The Heian Literary System: a tentative model. In: HOCKX, M.; SMITS, I. (Orgs.). Reading East Asian Writing: The Limits of Literary Theory. London: Routledge, p.92-116.

SEl, S. Makura no Sôshi — Nihon Koten Bungaku Zenshû, v.18. Tóquio: Shôgakukan, 2011. [枕草子]

Notes de Chevet. Tradução e notas de André Beaujard. Paris: Gallimard, 2000.

. The Pillow Book - the diary of a courtesan in tenth century Japan. Tradução e notas de Arthur Waley. Tóquio: Tuttle, 2011.

.The Pillow Book of Sei Shônagon. Tradução e notas de Ivan Morris. Londres: Penguin, 1971. SHIMONO, H. Prefacio. In: SEl, S. El Libro de la Almohada de la Dama Sei Shônagon. Tradução de Iván Pinto Román, Osvaldo Gavidia e Hiroko Shimono. Lima: Pontificia Universidad Católica del Perú, 2002. p.13-24.

THOMETZ, K. From the library of Diana Vreeland. Books are weapons, Nova lorque, mar. 2012. Disponível em: <http://www.the-private-library.com/2012/03/27/from-the-library-ofdiana-vreeland-2/>. Acesso em: 13 ago. 2015.

VREELAND, D. Diana Vreeland asks, why don't you. Harper's Bazaar, Nova lorque, jun. 2014. Disponivel em: <http://www.harpersbazaar.com/culture/features/a2620/diana-vreeland -why-dont-you/>. Acesso em: 12 ago. 2015. 
WAKISAKA, G.; CORDARO, M. Sobre a obra, a autora, o contexto e a tradução. In: SEI, S. O Livro do Travesseiro. Tradução de G. Wakisaka, J. Ota, L. Hashimoto, L. Yoshida e M. Cordaro. São Paulo: Editora 34, 2013. p.7-41.

WALLACE, J. Objects of Discourse: Memoirs by Women of Heian Japan. Michigan ZEAMI, M. Hagoromo de Zeami - o charme sutil. Tradução de Haroldo de Campos, Darci Kusano e Elza Doi. São Paulo: Estação Liberdade, 2005.

Recebido em: 15/08/2015 Aceito em: 09/11/2015

Referência eletrônica: CUNHA, Andrei. Texto e têxtil em $\bigcirc$ livro de travesseiro. Criação \& Crítica, n. 15, p. 20-40, dez. 2015. Disponível em: <http://revistas.usp.br/criacaoecritica>. Acesso em: dd mm aaaa.

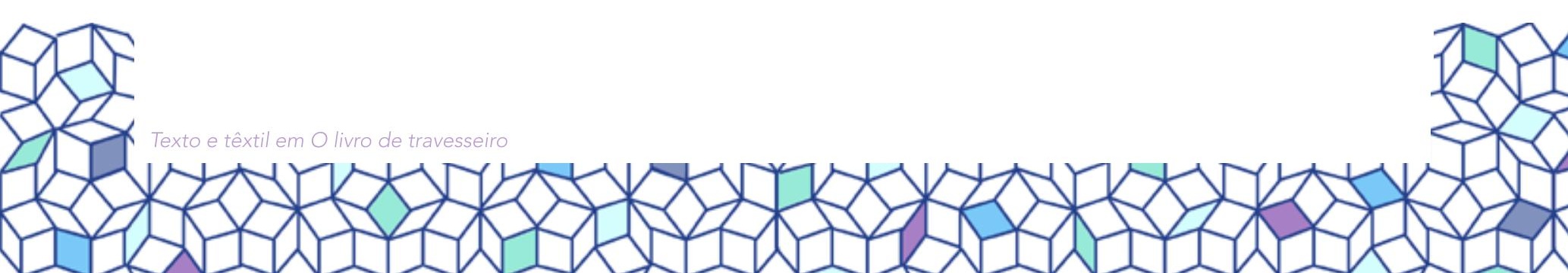

